\title{
Feasibility analysis of additive manufacturing method for graphene based super solar body mounted patch antenna for satellite applications
}

\author{
Prasanna Ram ${ }^{1}$ (D) Rachel Jeeva Light Rajakumaran ${ }^{1} \cdot$ Rashika Chithoor Santharam $^{1} \cdot$ Jahnavi Nancheri ${ }^{1}$. \\ Monika Gayathri Ogirala ${ }^{1}$
}

Received: 10 September 2019 / Accepted: 2 March 2020 / Published online: 10 March 2020

C) Springer Nature Switzerland AG 2020

\begin{abstract}
In this project, a Nano material based printed patch antenna structure has been integrated with a solar panel without affecting the optical efficiency of the solar panel. The proposed prototype is having the property of both antenna and solar module functionality. A graphene based CPW fed E-Shaped micro strip patch antenna which has a return loss of $-48.43 \mathrm{~dB}$ at resonant frequency of $2.1 \mathrm{GHz}$ which is best suitable for UMTS-2100 Band (2.15-2.18 GHz), GSM $(2.15-2.18 \mathrm{GHz})$ applications is printed on the solar panel using screen printing technique. In this project, conventional copper-based antennas are replaced with graphene-based antennas due to various advantages. In this experiment, the feasibility of material based body mounting antenna structure printing method is analysed. This proposed design model is best suitable for satellites where antennas occupy one-third of the satellite's size. By mounting the small printed antennas on the solar panel, the space complexity of the satellite system gets reduced by one-third of its initial dimensions.
\end{abstract}

Keywords Graphene · Screen printing · Body mounted antenna · Micro strip patch antenna · Solar panel efficiency

\section{Introduction}

In recent advancements in the satellite communication field like Small Sat and CubeSat which are very small in size, it is difficult to deploy antenna for communication and solar panel for energy harvesting within a small space. Hence integrating antenna with solar panel and making them as a single compact unit draws attention worldwide. The important consideration in this approach is the antenna which is integrated with the solar panel should radiate efficiently without degrading the efficiency of the solar panel with its shadowing property.

The state of the art integration methods can be broadly divided into two categories: Sub-solar and Super-solar [1].
In Sub-solar, the antennas are placed below the photovoltaic (PV) panel and in super-solar, the antennas are placed above the PV panel. Slot antennas that are placed beneath the solar panel in a manner that, the radiating surface is not shadowed by the solar cells $[2,3]$ were used in subsolar approach. In this configuration the radiating antenna element need to be very small and also located carefully between the solar cells. This configuration affects the performance of the antenna, as the solar cells act as superstrate and it is difficult to place the fabricated antenna under the after-market solar panel. So it is of less interest among researchers. Hence super solar method gains much interest.

Prasanna Ram, prasannaram88@gmail.com; Rachel Jeeva Light Rajakumaran, racheljeevalight@gmail.com; Rashika Chithoor Santharam, cs.rashika@gmail.com; Jahnavi Nancheri, jahnavi.nancheri@gmail.com; Monika Gayathri Ogirala, mnkgayathri@gmail.com | ${ }^{1}$ Vel Tech Rangarajan Dr Sagunthala R\&D Institute of Science and Technology, Avadi, Chennai, India. 
For super-solar approach both transparent and opaque patch antennas were used. Transparent antenna includes meshed antenna [4, 5], conformal slot antenna [6] and patch antenna printed with Transparent Conductive Oxides (TCO) like Indium Tin Oxide (ITO) [6] and silver coated polyester film(AgHT) [7-9] whereas opaque antenna comprises of slot antenna $[10,11]$ with small dimension of antenna shadowing the solar cells and patch antennas placed in the gap between the solar cells. Apart from these, this super-solar approach also include inverted F-shaped patch antennas that are placed vertically $[12,13]$ on the solar panel. Some comparative studies on transparent and meshed antenna were done in $[14,15]$ which shows that transparent antenna printed using TCOs are flexible as it can be placed anywhere on the solar panel and can be extended to arrays. Also, these transparent antennas can be fabricated easily on after-market solar panels. But it cannot be as efficient as meshed antenna. This meshed antenna is a bit difficult to design and fabricate when compared to patch antennas that can be printed uniformly on a smooth surface. Hence, an efficient antenna that can be easily fabricated on solar panel can solve this trade-off. One of the solution we examined is, graphene patch antenna printed on solar panel.

Graphene is a two-dimensional material with high flexibility, good tensile strength, high electrical conductivity [16] of about $10^{8} \mathrm{~S} / \mathrm{m}$ which is greater than that of silver $\left(6.25 \times 10^{7} \mathrm{~S} / \mathrm{m}\right)$ and copper $\left(5.8 \times 10^{7} \mathrm{~S} / \mathrm{m}\right)$ and very high electron mobility. In addition to these it also possesses good optical properties that are worth to be noted. Graphene is highly transparent i.e., single layer of graphene allows $97.7 \%$ of light [17] to pass through it. Double layer of graphene increases electrical conductivity and absorbs only $4.6 \%$ of light which can compete with the existing TCO antenna. Hence, it can be used as transparent conductors. The high conductivity and radiation absorption nature of graphene along with the optical transparency make it the most suitable material for designing efficient patch antenna on solar panel without degrading the efficiency of the solar panel. One more advantage of using graphene is its weight. Since graphene is only one-sixth of copper density, it reduces the weight of the antenna payload because of its amorphous form of existence.

In our work an E-shaped patch antenna was printed with graphene Nano conductive ink using screen printing technique on the solar panel. In this paper we have discussed the antenna parameters and the properties of the printed structure, selection of printing mechanism, customization of printing material and the efficiency of solar panel mounted with antenna.

\section{Antenna design}

In this paper, an E-shaped micro strip patch antenna has been designed by introducing rectangular slots to the conventional basic rectangular micro strip patch which has a length of $25 \mathrm{~mm}$ and width of $31 \mathrm{~mm}$ and is fed with CPW feeding mechanism as shown in the Fig. 1. E-shaped antenna provides wide bandwidth [18], dual band [19] and enhanced antenna parameters [18]. Along with this it also occupies less area which reduces the shadowing and also reduces the quantity of conductive material used to print the antenna structure. Hence, this shape is chosen for experimentation.

The proposed prototype is based on super-solar approach that is the designed antenna is printed on after-market solar panel. In this approach, mostly the glass layer above the solar panel acts as substrate for the patch antenna. The ground plane, for the antenna to radiate effectively is of great concern, since it could also affect the solar panel efficiency. Some solutions so far used were meshed ground plane with coaxial feeding $[1,5]$, body of the satellite as ground plane [11], separate ground plane that need to be electrically isolated from the solar panel $[6,10]$ and the solar cell itself as ground plane [8] with line feeding or electromagnetic coupling. All these methods are complex in fabrication and feeding. So, in order to reduce the fabrication complexity CPW feeding [7] is used. In this feed the patch and the ground plane is printed on single side of the substrate which makes the fabrication easier. The chosen micro strip patch is designed on a glass substrate of length $31 \mathrm{~mm}$, width $41 \mathrm{~mm}$ and $1.6 \mathrm{~mm}$ thickness with dielectric constant of 4.4. The antenna is fed with $50 \Omega$ micro strip line using CPW based inset feeding mechanism.

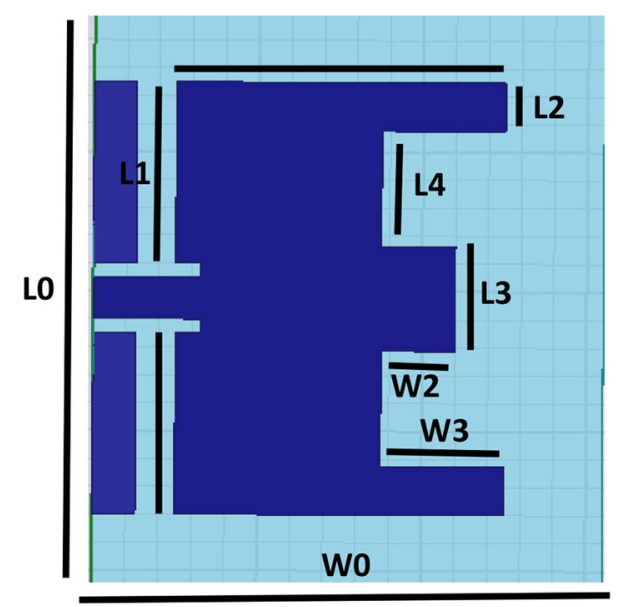

Fig. 1 Proposed E-shaped micro strip patch antenna 
This proposed antenna was designed and simulated in ANSYS HFSS and the results were obtained.

\section{Selection of printing}

Graphene is the most widely studied material for printed electronics. Common printing technologies used were inkjet, screen printing, flexographic and gravure printing and offset lithography [20]. Apart from these spraying and doctor blading technique were also used in printing micro strip patch antennas. Flexographic and offset lithography were least methods used in printed electronics. Spraying is a good method but because of uneven coating thickness [21] it will not be suitable for experimentation. Doctor blading [22] is a simple method to spread highly viscous graphene ink but its accuracy is less when compared to inkjet and screen printing because of the thickening lattice structure on the top when compared to the bottom lattices.

Inkjet printing can be done with low viscosity graphene ink of about 10-12 mPa s [23] which is highly accurate and also high cost. This type of printing is very useful in flexible printed electronics [24]. In inkjet printing there is a possibility for agglomeration of graphene nano particles due to the low viscosity nature of the ink that is used. And also inkjet printing is best technique when the substrate used is very thin. The substrate used here is the glass on the solar panel with thickness of $1.6 \mathrm{~mm}$. The surface of the glass is also very polished so the adhesion of low viscosity conductive ink is poor because of the poor atomic bonding over the solar panel surface.

Screen printing is the best method when accuracy, cost and conductivity [21] are of main concern. In this technique, the thickness of the substrate is not a problem. The main concern here is the viscosity of the graphene conductive ink because low viscosity inks cannot be used for screen printing [20]. Also, high viscosity inks can be printed on smooth polished surfaces like glass, which is used as the substrate in our prototype. Hence screen printing is chosen for the fabrication of the prototype but the graphene ink used for this should be properly customized for the printing.

\section{Customization of printing material}

In graphical printing the ink is composed of pigments, binder, solvents and additives [20]. For printed electronics the pigment is replaced by conductive materials. The graphene conductive ink prepared for our project is composed of low density graphene powder, binder dispersions and solvent. The high viscous graphene ink was prepared by mild heating of low density graphene powder with binder at a ratio of 1:2 and mixed with isopropyl alcohol which is the solvent used. In order to maintain the conductivity in the same line after printing, no additives are added.

\section{Fabrication}

After solvent exchange, the graphene ink was applied to the substrate by screen printing using $45^{\circ}$ angle polyurethane squeegees, at printing speed of $50 \mathrm{~mm} / \mathrm{s}$ followed by drying in air at $100^{\circ} \mathrm{C}$ for $5 \mathrm{~min}$. The thickness of printing is measured as $23 \mu \mathrm{m}$. Subsequently, printed structures were thermally cured at $350^{\circ} \mathrm{C}$ for $30 \mathrm{~min}$ in air and finally, compression rolled. Printing was done with EKRA E2 semi-automatic screen and stencil printer (ASYS Group) in air at controlled temperature and relative humidity. But graphene is a bit brittle like ceramic which might cause mechanical issues which can be solved by coating the micro strip patch with polymer-based enamel without affecting the efficiency of the antenna and its performance.

\section{Results and inference}

The designed CPW Fed E shaped micro strip patch antenna model as shown in Fig. 1 has two reflections below $\left|S_{11}\right|=-10 \mathrm{~dB}$ when simulated using HFSS software. It has return loss values of $-30.48 \mathrm{~dB}$ and $-11.14 \mathrm{~dB}$ at resonant frequencies of $2.1 \mathrm{GHz}$ and $2.7 \mathrm{GHz}$ respectively as shown in the Fig. 2. It has VSWR values of 0.51 and 4.84 for $2.1 \mathrm{GHz}$ and $2.7 \mathrm{GHz}$ respectively as shown in the Fig. 3 . It has impedance bandwidth of $25.87 \%$ at $\left|S_{11}\right| \leq-10 \mathrm{~dB}$ at a range of $2.13-2.77 \mathrm{GHz}$ and has a reduced area of $617.55 \mathrm{~mm}$ (i.e. $79.6 \%$ of the conventional basic rectangular patch area). A 3-D view of the antenna gain which $2.7 \mathrm{~dB}$ is given in Fig. 4. From the results, the antenna design is suitable for UMTS-2100 Band $(2.11-2.17 \mathrm{GHz})$ applications.

The proposed Micro strip patch has been fabricated using graphene material as shown in the Fig. 5 using screen printing technique as mentioned earlier in Sect. 5 . When measured using network analyser, we obtained a return loss of $-48.43 \mathrm{~dB}$ at resonant frequency of $2.09 \mathrm{GHz}$ as shown in the Fig. 6 . The shift in the obtained value is due to the conductivity nature of the material used. The VSWR value lies between 0 and 2 as shown in the Fig. 7. It has an impedance bandwidth of $25.87 \%\left(\left|S_{11}\right| \leq-10 \mathrm{~dB}\right)$ in the frequency range of $2.06-2.11 \mathrm{GHz}$ with centre frequency $2.09 \mathrm{GHz}$ which covers UMTS-2100 Band applications. 


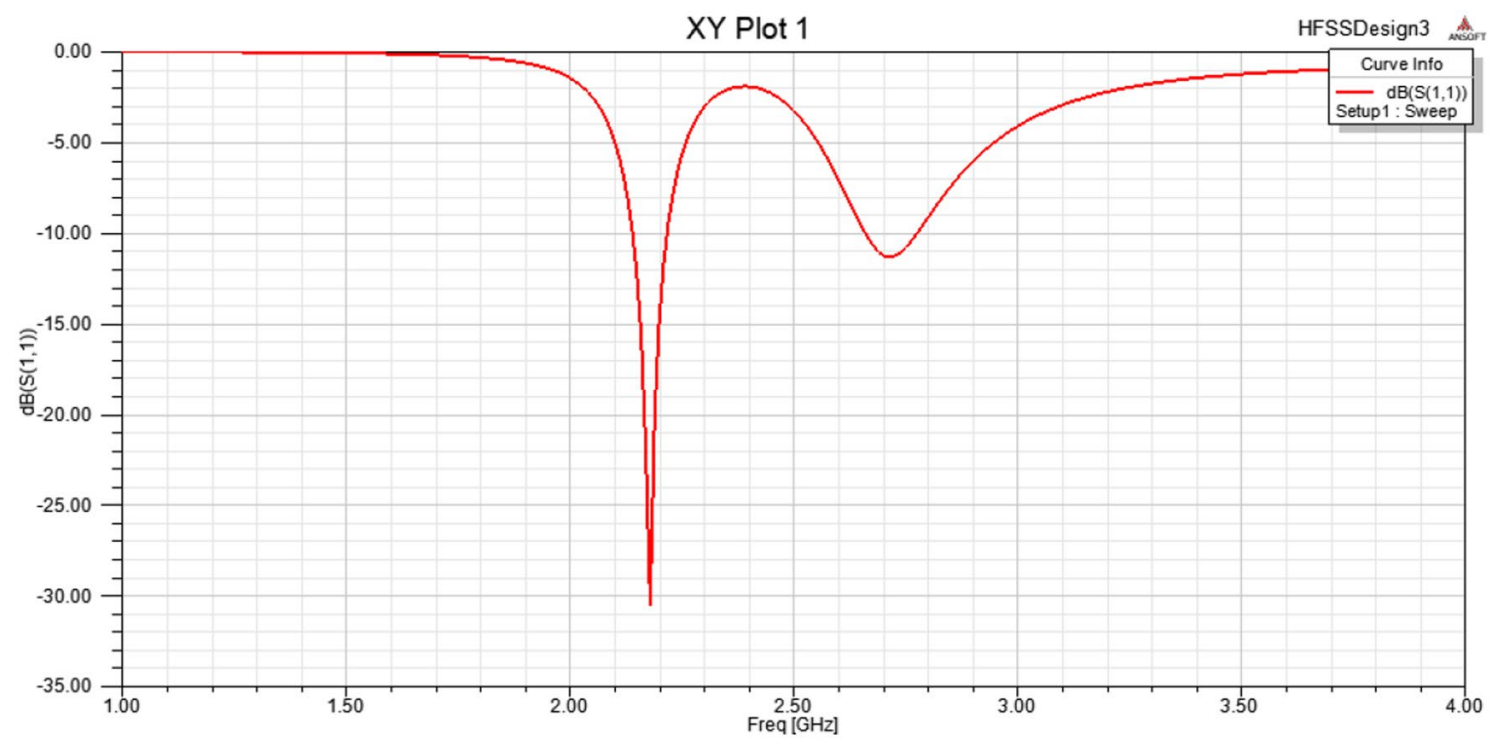

Fig. 2 Simulated return loss graph of the proposed design

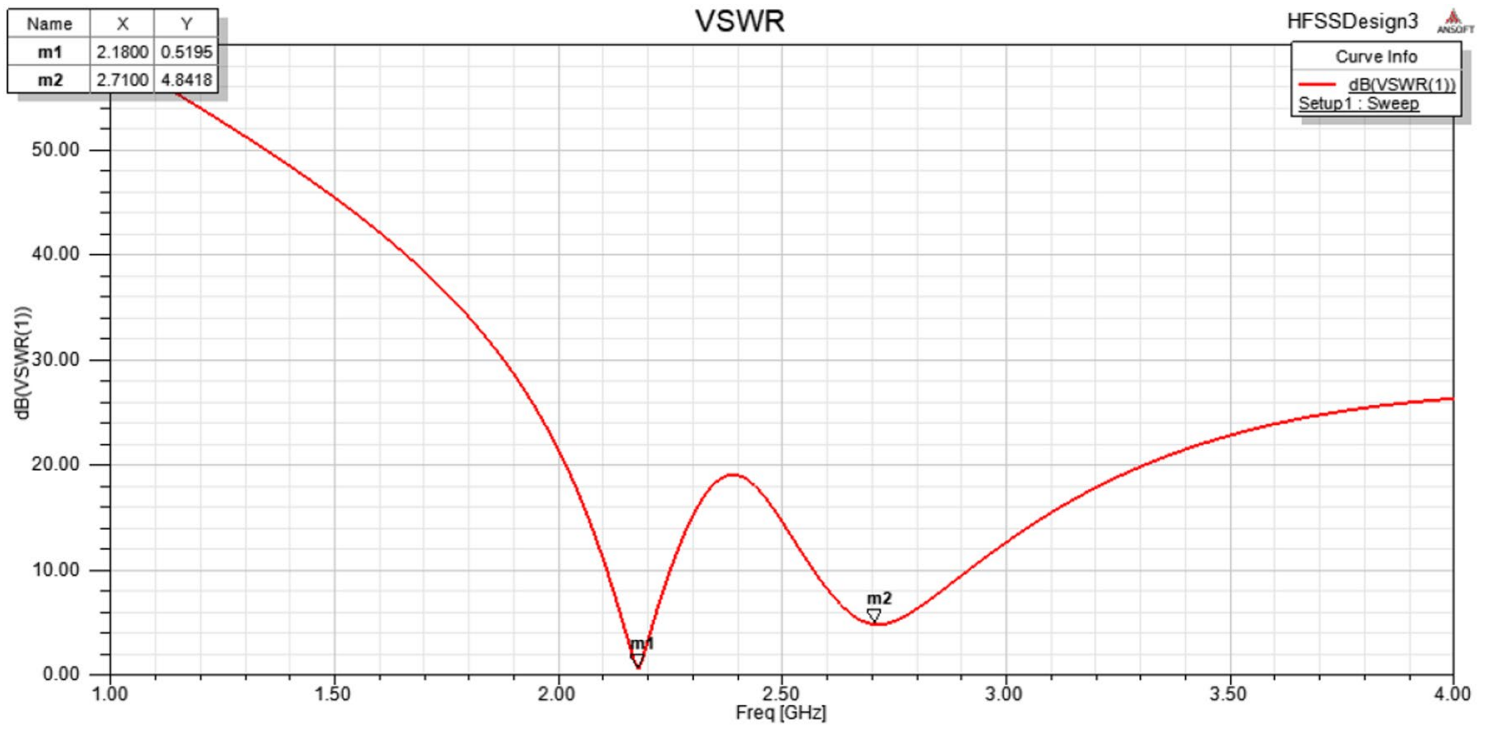

Fig. 3 Simulated VSWR graph of the proposed design

The polarization is observed as linear. This will be more suitable for near field communication in omni directional range.

The efficiency of the solar panel used without printing is $3 \mathrm{~W}$. With material printing the value obtained is $2.75 \mathrm{~W}$ and the efficiency is degraded at a rate of $9.09 \%$ because of the shadowing caused by the printed antenna structures. By using screen printing the percentage of opaqueness is reduced and studied. It can be further improved by adapting atomic deposition mechanisms which are costlier than the used technique.
Some of the body mounted patch antenna on Solar panel that operate around $2-3 \mathrm{GHz}$ that are found in the literature are compared in Table 1. Transparent antenna for solar panel found in the literature uses AgHT-4 film or Mesh type antenna. In our work, we have designed graphene based solid patch antenna, which operates around $2.45 \mathrm{GHz}$ with a gain of $2.75 \mathrm{GHz}$.

Graphene will be having less scattering effect in patch antenna structures and this make graphene more 

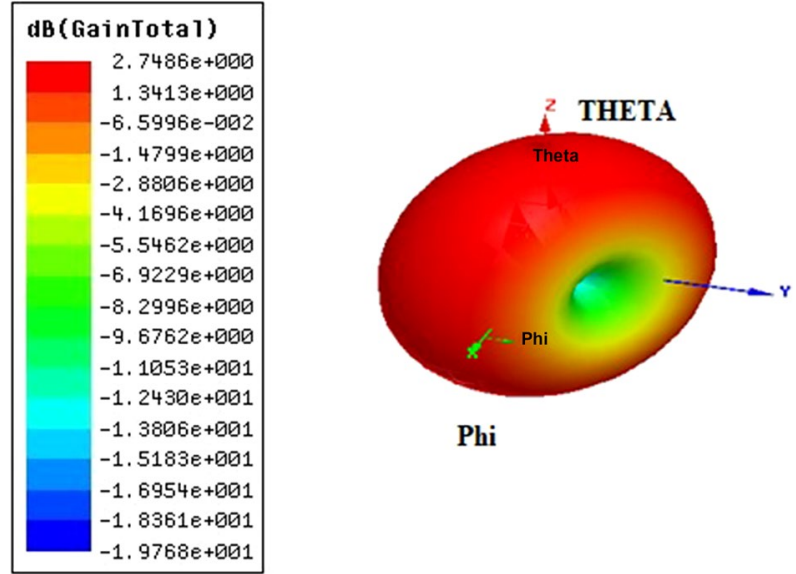

Phi

Fig. 4 Simulated 3D polar plot of gain of the proposed design

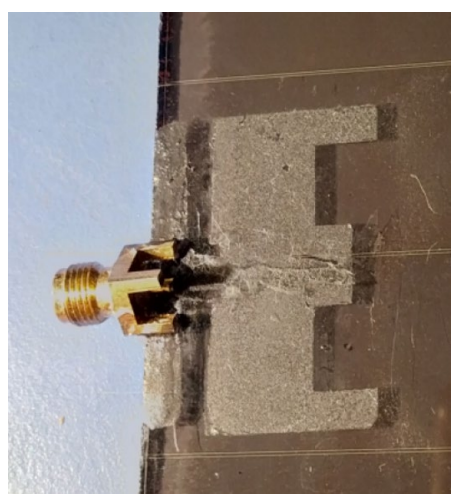

Fig. 5 Fabricated prototype of graphene based CPW fed E-shaped micro strip patch antenna on the solar panel

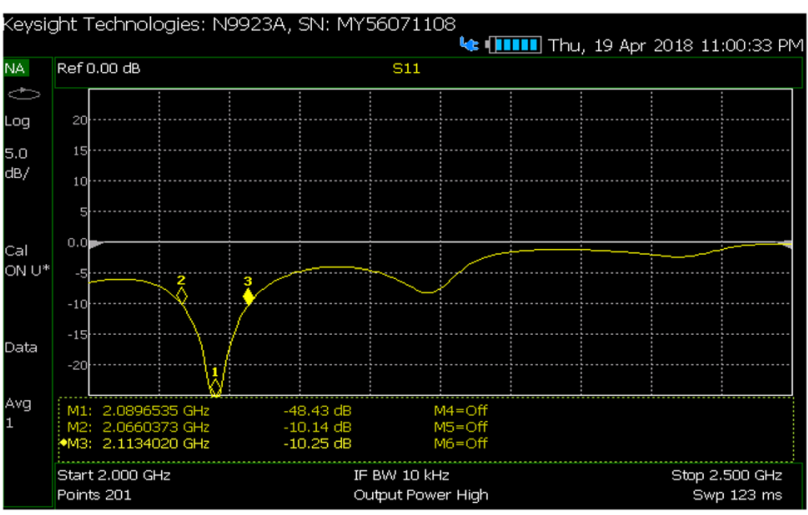

Fig. 6 Measured return loss graph of the proposed design

suitable for patch antenna application over solar panel. The microwave absorption of the graphene material is very high because of its material property.

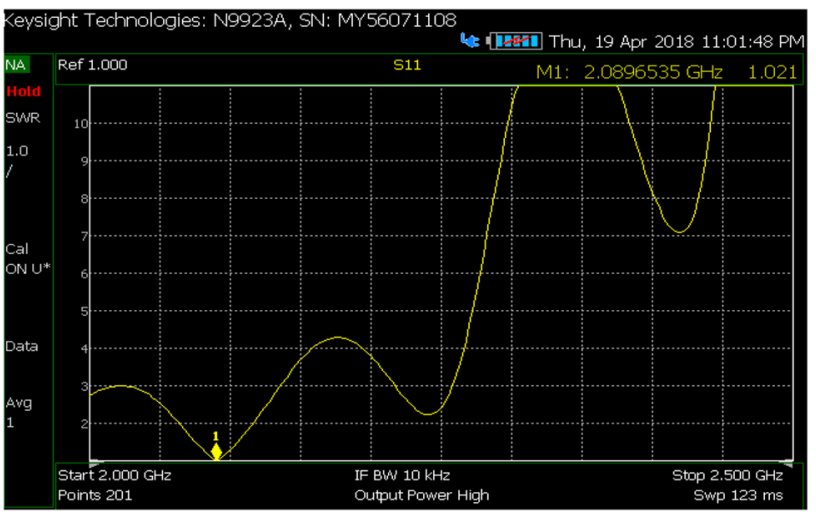

Fig. 7 Measured VSWR graph of the proposed design

\section{SEM characterization of low density graphene powder and printed graphene layer}

The SEM characterization in Fig. 8 shows the imaging of the low density graphene powder which is in the range of $10 \mu \mathrm{m}$. This is used as the fabrication material by combining it with the bonding and makes it suitable for the screen printing. This low density graphene powder will be more suitable for the screen printing as this will give uniform bonding with the composites.

When the granule size increases there will be a porosity formation during printing and the suppression of material properties will be observed. So to maintain the uniform and proper bonding and for maintaining the property of the material low density graphene powder is chosen.

The thickness of the printed graphene layer on the solar panel is also characterized using SEM. The sample is measured for its thickness and the coated levels. SEM will be more advanced technique for this method. It is expected to have the thickness in the range of $100-150 \mu \mathrm{m}$. It may vary due to the effect of the curing and the sintering environmental conditions. Viscosity of the material used and the nozzle pressure are very important to maintain the thickness in the exact range. The thermal absorption of the substrate is highly important in order to maintain the thickness in the expected range. When these parameters are changed there will be a change in the thickness due to the external conditions.

Figure 9 shows the size of the single layer of the printed graphene patch over the solar panel. This shows that the thickness of the single patch structure printed over the solar panel measures about $100 \mu \mathrm{m}$ or $0.1 \mathrm{~mm}$ which is achieved through the screen printing techniques. 
Table 1 Comparison of body mounted antenna on solar panel found in literature

\begin{tabular}{|c|c|c|c|c|}
\hline References & Type of antenna & $\begin{array}{l}\text { Resonant frequency } \\
(\mathrm{GHz})\end{array}$ & $\begin{array}{l}\text { Antenna gain } \\
\text { (dB) }\end{array}$ & $\begin{array}{l}\text { Trans- } \\
\text { parency } \\
(\%)\end{array}$ \\
\hline Liu et al. [1] & Meshed silver epoxy patch antenna on solar panel & 2.4 & 4.94 & 95.9 \\
\hline Turpin and Baktur [4] & Meshed copper patch antenna on solar panel & 2.61 & 5.2 & 93 \\
\hline Peter et al. [7] & AgHT-4 CPW fed patch antenna on solar panel & 2.55 & 9.8 & 75 \\
\hline RooOns et al. [8] & AgHT-4 rectangular patch antenna on solar panel & 3.5 & 3.96 & 92 \\
\hline Proposed Antenna & $\begin{array}{l}\text { Graphene based CPW fed E-shaped patch antenna on } \\
\text { solar panel }\end{array}$ & 2.45 & 2.75 & 90 \\
\hline
\end{tabular}

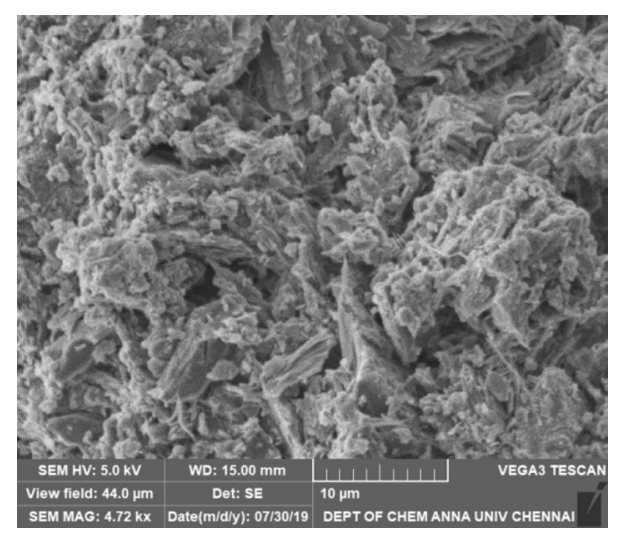

Fig. 8 SEM image of low density graphene powder

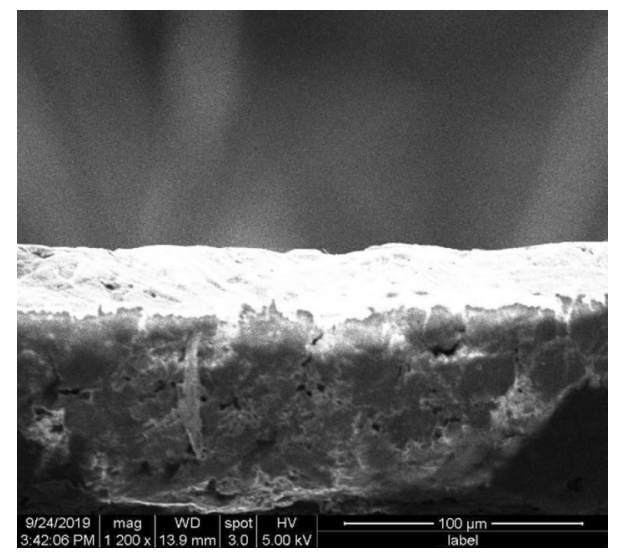

Fig. 9 SEM image of single layer printed graphene sample

\section{Feasibility of mounting antenna on solar panel}

This study involves mounting of graphene based patch antenna on the solar panel. In this work, the screen printing technique is used to print graphene based patch antenna over the solar panel. Here the substrate material is made up of glass. So, the prime factors such as viscosity, atomic bonding, atomic radii, temperature of sintering, bonding material, efficiency of the antenna, efficiency of the solar panel are very much important. The primary concerns in this work are effect of antenna on the solar panel and the effect of solar panel on the antenna performance. The effect of antenna on the solar panel is discussed in the results and it is observed that a deviation of $0.25 \mathrm{~W}$ is noted with antenna mounting. With respect to the antenna parameters, there is no much loss inferred.

\section{Conclusion}

In this paper, a graphene based CPW fed E-shaped micro strip patch antenna has been printed on the solar panel using screen printing technique and the antenna parameters are analysed and discussed. It is inferred that, due to the effect of graphene material, the antenna parameters are enhanced and obtained at the same frequency expected which is more suitable for microwave applications. In this project the feasibility of screen printing method for graphene antenna structure printing for body mounted applications are analysed. By using graphene material the antenna parameters are improved up to a considerable level and the efficiency of the solar panel is not degraded much because of the semitransparent property of the graphene conductive ink. By these experiments the duality nature of integrated antenna module with solar panel is achieved and studied for its effectiveness without disturbing the individuality of the two modules.

\section{Compliance with ethical standards}

Conflict of interest On behalf of all authors, the corresponding author states that there is no conflict of interest. 


\section{References}

1. Liu X, Jackson DR, Chen J, Liu J, Fink PW, Lin GY, Neveu N (2017) Transparent and non transparent microstrip antennas on a cubesat: novel low-profile antennas for cubesats improve mission reliability. IEEE Antennas Propag Mag 59(2):59-68. https:// doi.org/10.1109/map.2017.2655529

2. Caso R, Garroppo R, Giordano S, Manara G, Michel A, Nepa P, Nenna G (2015) Antennas and photovoltaic panels: toward a green internet of things. In: 2015 IEEE 2nd world forum on internet of things (WF-loT). https://doi.org/10.1109/wfiot.2015.7389039

3. Jones T, Grey JP, Daneshmand M (2018) Solar panel integrated circular polarized aperture-coupled patch antenna for cubesat applications. IEEE Antennas Wirel Propag Lett. https://doi. org/10.1109/lawp.2018.2869321

4. Turpin TW, Baktur R (2009) Meshed patch antennas integrated on solar cells. IEEE Antennas Wirel Propag Lett 8:693-696. https ://doi.org/10.1109/lawp.2009.2025522

5. Nashad F, Foti S, Smith D, Elsdon M, Yurduseven O (2016) Development of transparent patch antenna element integrated with solar cells for Ku-band satellite applications. In: 2016 loughborough antennas and propagation conference (LAPC). https://doi. org/10.1109/lapc.2016.7807579

6. Yekan T, Baktur R (2017) Conformal integrated solar panel antennas: two effective integration methods of antennas with solar cells. IEEE Antennas Propag Mag 59(2):69-78. https://doi. org/10.1109/map.2017.2655577

7. Peter T, Rahman TA, Cheung SW, Nilavalan R, Abutarboush HF, Vilches A (2014) A novel transparent UWB antenna for photovoltaic solar panel integration and RF energy harvesting. IEEE Trans Antennas Propag 62(4):1844-1853. https://doi.org/10.1109/ tap.2014.2298044

8. Roo-Ons MJ, Shynu SV, Ammann MJ, McCormack SJ, Norton B (2011) Transparent patch antenna on a-Si thin-film glass solar module. Electron Lett 47(2):85. https://doi.org/10.1049/ el.2010.7397

9. Zamudio ME, Tawk Y, Costantine J, Ayoub FN, Christodoulou CG (2015) Design of a transparent spiral antenna for energy harvesting. In: 2015 IEEE international symposium on antennas and propagation and USNC/URSI national radio science meeting. https://doi.org/10.1109/aps.2015.7305030

10. Tariq S, Baktur R (2015) Circularly polarized UHF up- and downlink antennas integrated with CubeSat solar panels. In: 2015 IEEE international symposium on antennas and propagation and USNC/URSI national radio science meeting. https://doi. org/10.1109/aps.2015.7305101

11. Alam T, Islam MT, Ullah MA, Rahmatillah R, Aheieva K, Lap CC, Cho M (2018) Design and compatibility analysis of a solar panel integrated UHF antenna for nanosatellite space mission. PLoS ONE 13(11):e0205587. https://doi.org/10.1371/journ al.pone.0205587

12. Tawk Y, Costantine J, Ayoub F, Christodoulou CG (2018) A communicating antenna array with a dual-energy harvesting functionality [wireless corner]. IEEE Antennas Propag Mag 60(2):132-144. https://doi.org/10.1109/map.2018.2796025

13. Narbudowicz A, Heberling D, O'Conchubhair O, Ammann MJ (2016) Integration of antennas with sun-tracking solar panels. Electron Lett 52(15):1325-1327. https://doi.org/10.1049/ el.2016.1040

14. Yasin T, Baktur R, Furse C (2011) A comparative study on two types of transparent patch antennas. In: 2011 XXXth URSI general assembly and scientific symposium. https://doi. org/10.1109/ursigass.2011.6050441

15. Nogi K, Kuwahara Y (2018) Design of transparent patch antenna for smallsats. In: 2018 IEEE international workshop on electromagnetics: applications and student innovation competition (iWEM). https://doi.org/10.1109/iwem.2018.8536703

16. Subrina S, Kotchetkov D (2008) Simulation of heat conduction in suspended graphene flakes of variable shapes. J Nanoelectron Optoelectron 3:249-269. https://doi.org/10.1166/jno.2008.303

17. https://www.azooptics.com/Article.aspx?ArticlelD $=1537$

18. Sheik BA, Sridevi PV, Raju PVR (2018) Comparison of inset-fed rectangular and E-shaped antenna arrays for LTE and Wi-Fi applications. In: 2018 conference on signal processing and communication engineering systems (SPACES). https://doi.org/10.1109/ spaces.2018.8316304

19. Kumar GS, Shanthi V, Goud EU (2017) Dual-band tunable adapted E-shaped microstrip patch antenna. In: 2017 2nd IEEE international conference on recent trends in electronics, information and communication technology (RTEICT). https://doi. org/10.1109/rteict.2017.8256927

20. Ng LW, Hu G, Howe RC, Zhu X, Yang Z, Jones CG, Hasan T (2018) Printing of graphene and related 2D materials: technology, formulation and applications, 1st edn. Springer, Berlin

21. Pan K, Fan Y, Leng T, Li J, Xin Z, Zhang J, Hu Z (2018) Sustainable production of highly conductive multilayer graphene ink for wireless connectivity and loT applications. Nat Commun. https ://doi.org/10.1038/s41467-018-07632-w

22. Akbari $M$, Khan MWA, Hasani M, Bjorninen $T$, Sydanheimo $L$, Ukkonen $L$ (2016) Fabrication and characterization of graphene antenna for low-cost and environmentally friendly RFID tags. IEEE Antennas Wirel Propag Lett 15:1569-1572. https://doi. org/10.1109/lawp.2015.2498944

23. Secor EB, Prabhumirashi PL, Puntambekar K, Geier ML, Hersam MC (2013) Inkjet printing of high conductivity, flexible graphene patterns. J Phys Chem Lett 4(8):1347-1351. https://doi. org/10.1021/jz400644c

24. Torrisi F, Hasan T, Wu W, Sun Z, Lombardo A, Kulmala TS, Ferrari AC (2012) Inkjet-printed graphene electronics. ACS Nano 6(4):2992-3006. https://doi.org/10.1021/nn2044609

Publisher's Note Springer Nature remains neutral with regard to jurisdictional claims in published maps and institutional affiliations. 